Cahiers $d u$ MONDE RUSSE

\section{Cahiers du monde russe}

Russie - Empire russe - Union soviétique et États indépendants

$43 / 4 \mid 2002$

Intellectuels et intelligentsia

\title{
Julie A. Cassiday, The enemy on trial
}

\section{Martine Godet}

\section{OpenEdition \\ Journals}

Édition électronique

URL : https://journals.openedition.org/monderusse/4031

DOI : 10.4000/monderusse.4031

ISSN : $1777-5388$

Éditeur

Éditions de l'EHESS

Édition imprimée

Date de publication : 30 décembre 2002

Pagination : 727-729

ISBN : 2-7132-1796-2

ISSN : $1252-6576$

\section{Référence électronique}

Martine Godet, "Julie A. Cassiday, The enemy on trial », Cahiers du monde russe [En ligne], 43/4 |

2002, mis en ligne le 17 juin 2009, consulté le 03 septembre 2022. URL : http://

journals.openedition.org/monderusse/4031; DOI : https://doi.org/10.4000/monderusse.4031

Ce document a été généré automatiquement le 3 septembre 2022.

Tous droits réservés 


\title{
Julie A. Cassiday, The enemy on trial
}

\author{
Martine Godet
}

\section{RÉFÉRENCE}

Julie A. CASSIDAY, The enemy on trial. Early Soviet courts on stage and screen.

DeKalb, Northern Illinois University Press, 2000, 260 p.

1 Dans cet essai fortement original, Julie A. Cassiday montre comment, dans les années 1920, le théâtre et le cinéma d'avant-garde sont utilisés comme véhicules de la propagande officielle soviétique en mettant en scène des simulacres de procès publics. La création de l'Homme Nouveau et l'éducation des masses au nouvel ordre social passent par la stigmatisation d'un ennemi public qui permet de renforcer le procès de l'État contre ceux que celui-ci désigne comme criminels, politiquement dangereux, contrerévolutionnaires, etc. L'auteur observe ainsi une convergence des paradigmes théâtraux et cinématographiques dans ces " procès-fiction ".

2 Julie Cassiday retrace dans l'introduction les origines de la «théâtralité révolutionnaire ", avec les apports successifs de Vjačeslav Ivanov, Nikolaj Evrejnov et Platon Keržencev, théoricien du proletkul't, qui font du théâtre le creuset de la révolution; puis celles, mieux connues, du cinéma, « le plus important des arts » pour Lenin, et son apport théorique à la révolution. Très vite, le nouveau pouvoir réalise le formidable impact du tribunal sur les masses ainsi que le potentiel à la fois dramatique et éducatif des procès politiques. En effet, les nouveaux fonctionnaires du gouvernement soviétique ont souvent été jugés dans le cadre de tels procès avant 1917 et sont conscients de la publicité que ceux-ci offraient à la cause révolutionnaire. Ces "précédents impériaux » sont décrits dans le premier chapitre, avec notamment le procès de Vera Zasulič en 1878. L'auteur fait ressortir toute la théâtralité de cet événement, l'empathie et l'identification du public avec l'accusée qui fait figure de martyre. Elle évoque ensuite rapidement les premiers procès de l'ère bolchevique (1918), calqués sur ceux de la Révolution française. En 1918, Dziga Vertov commence à tourner des actualités filmées intitulées «Kinonedelja» qui couvrent un certain nombre de 
procès. En 1922, le procès des SR marque le début des vrais procès-spectacles qui mettent en avant le rôle des spectateurs et encouragent une participation forte de l'audience, dans le but d'effacer la frontière entre la scène et la vie réelle. Le public, étroitement contrôlé, est appelé à participer au verdict. Vertov couvre ce procès dans « Kinopravda ».

Le deuxième chapitre est consacré à l'agitsud (tribunal de propagande) qui fonctionne de 1922 à 1928 environ. Destiné à éduquer les masses, l'agitsud consiste en une séance de tribunal mise en scène au théâtre. Pour émouvoir davantage, il utilise le biais du mélodrame. Au moyen de procès-modèles (pokazatel'nye processy), les bolcheviks visent à faire jouer aux citoyens un rôle déterminant dans l'exercice de la justice prolétarienne. Pour renforcer l'impact de propagande du procès public, l'objectif est de basculer de la stigmatisation d'un ennemi externe (comme dans le procès des SR), à celle d'un ennemi interne. Ainsi le procès public, au théâtre, est censé atteindre le spectateur au cœur de sa vie quotidienne et accroître sa vigilance pour l'amener à découvrir toutes les formes d'activités et d'attitudes contre-révolutionnaires. Démasquer l'ennemi dans le cadre d'un procès amène l'accusé à confesser son crime, à se repentir de ses méfaits, puis à demander sa réintégration dans la société. Ainsi est reproduit le rituel religieux de l'orthodoxie russe. Le triple paradigme nécessaire à la création de l'Homme Nouveau est en place. Le spectateur de ce simulacre de procès est encouragé à y participer activement en tant que jury. Ouvrier ou paysan le plus souvent illettré, il est extrêmement malléable et a tendance à confondre l'agitsud avec un "vrai » procès. Le spectateur doit s'identifier à l'accusé sur scène, découvrir en son for intérieur le même potentiel criminel et formuler la même autocritique. Le motif d'accusation relève le plus souvent, à cette période, de déviations d'ordre moral et social - inefficacité dans le travail, débauche, alcoolisme, tabagisme, " arriération », etc. -, et le but de l'agitsud est d'inculquer au spectateur une nouvelle moralité socialiste. Dans ces simulacres de procès, le comportement déviant de l'inculpé est imputé au mode de vie de l'Ancien Régime. Des origines prolétaires, un désir manifeste de repentance et la gratitude envers les autorités soviétiques assurent à l'accusé la reconnaissance de son innocence.

4 Moyen de propagande particulièrement efficace, l'agitsud disparaît à la fin des années 1920. Son déclin commence vers 1925, au moment où les films de fiction qui mettent en scène des procès acquièrent plus de visibilité (chapitre 3). L'activité cinématographique est étroitement encadrée par Anatolij Lunačarskij, commissaire à l'Éducation, qui prône le mélodrame comme genre le plus propre à séduire l'audience populaire. Ce n'est qu'à partir de la seconde moitié des années 1920 que ces films reprendront à l'écran des thèmes proches de ceux de l'agitsud (en désignant comme accusés paysans et prolétaires sortis momentanément du droit chemin, byvšie ljudi) avant d'élargir la catégorie des ennemis aux petits bourgeois, bureaucrates, etc. Julie Cassiday développe plusieurs analyses de films offrant une possibilité de confrontation entre agitsud et mélodramefiction: Le cordonnier de Paris (Friedrich Ermler, 1927), Saba (Mihail Čiaurali, 1929), Le bureaucrate du gouvernement (Ivan Pyr'ev, 1930). Il en ressort que si, au début des années 1920, on observait une prédominance du théâtre, vers la fin de la décade se produit un effet de bascule, et le cinéma l'emporte définitivement.

L'auteur montre ensuite (ch. 4 et 6) que les premiers « vrais » grands procès publics de la fin de la décennie (affaire de Chakhty/1928, procès du parti industriel/1930, procès des Metro-Vickers/1933) intégreront en retour des éléments tirés de la mise en scène théâtrale ou cinématographique: accusés sous contrôle, aveux appris par cœur, 
interrogatoires préparés d'avance. Cette interaction constitue l'une des thèses de l'auteur selon laquelle le public aurait dès lors assimilé d'avance, par le biais de la fiction, la mise en scène des grands procès à venir de 1936-1938, notamment ceux de Buharin et de Rykov. Au travers de la fiction, le schéma unique du juge, du criminel et du spectateur (dont la participation active au procès est l'un des éléments essentiels du spectacle) aura permis à l'institution du procès public d'atteindre - comme un signe avant-coureur - le pays tout entier.

6 L'approche globale de l'ouvrage est très marquée par les cultural studies et la sémiologie, ce qui rend parfois le style obscur et un peu jargonnant, mais le lecteur est séduit par la grande érudition dont fait preuve Julie Cassiday. Ses analyses de films, enlevées et incisives, sont un régal, notamment celles des Aventures extraordinaires de Mr. West au pays des bolcheviks de Lev Kulešov, ou de La carte du parti de Ivan Pyr'ev. Pour le théâtre, citons son étude très originale de La punaise de Vladimir Majakovskij. Le mérite principal de l'ouvrage est d'apporter un éclairage original sur la genèse des grands procès dans l'imaginaire du spectateur, même si la thèse de l'auteur peut paraître provocatrice. 